\title{
Diabetes Management and Healthcare Resource Use When Intensifying from Basal Insulin to Basal-Bolus: A Survey of Type 2 Diabetes Patients
}

\author{
Kathryn M. Pfeiffer · Amaury Basse $\cdot$ Xin Ying Lee $\cdot$ Laura Tesler Waldman
}

Received: June 21, 2018 / Published online: August 17, 2018

(C) The Author(s) 2018

\begin{abstract}
Introduction: Currently, there is limited knowledge about the experiences and challenges type 2 diabetes (T2D) patients face when intensifying from basal insulin to more complex regimens. The purpose of this study was to examine the experiences of adults with T2D who have been intensified to a basal-bolus insulin regimen, including challenges related to intensification, medication adherence issues, non-persistence, and healthcare resource use related to intensification.
\end{abstract}

Methods: A web-based survey of adults diagnosed with T2D and currently treated with basal insulin was conducted in the UK and the USA. The analysis sample was restricted to respondents with current/recent basal-bolus treatment $(n=398)$ and divided into three analysis groups: (1) "basal-bolus adherent" (current basal-bolus treatment with at least 90\% adherence); (2) "basal-bolus non-adherent" (current

Enhanced digital features To view enhanced digital features for this article go to https://doi.org/10.6084/ m9.figshare.6886943.

K. M. Pfeiffer $(\bowtie) \cdot$ L. T. Waldman

The Brod Group, 219 Julia Avenue, Mill Valley, CA 94941, USA

e-mail: kate@thebrodgroup.net

A. Basse - X. Y. Lee

Novo Nordisk A/S, Vandtaarnsvej 114, 2860 Søborg, Denmark basal-bolus treatment with less than $80 \%$ adherence); and (3) "stopped bolus" (discontinued bolus in past 12 months).

Results: Basal-bolus non-adherent respondents reported fewer discussions with their healthcare providers (HCPs) before starting bolus and more frequent difficulties with and worries about taking bolus insulin compared to basalbolus adherent and stopped bolus groups. The most frequently reported reasons for discontinuing bolus were related to the complicated nature of regimen, including too complicated to calculate bolus doses $(25.7 \%)$, too complicated to regulate food in relation to bolus (20.7\%), and too complicated to keep track of taking two different insulins (18.6\%). Respondents who stopped bolus reported more frequent HCP visits related to diabetes compared to the basal-bolus adherent and basal-bolus non-adherent groups.

Conclusion: Results suggest that the complicated nature of basal-bolus therapy contributes to the difficulties that T2D patients have with the regimen and to non-persistence. Physician and patient education may help patients address these treatment challenges to improve basal-bolus adherence and persistence, which could reduce healthcare resource use and costs. Less complex regimens may be appropriate for patients with persistent treatment difficulties.

Funding: Novo Nordisk A/S. 
Keywords: Basal-bolus insulin therapy; Diabetes management; Diabetes, type 2; Healthcare resource use; Insulin intensification

\section{INTRODUCTION}

Timely and effective blood glucose control is critical for the management of type 2 diabetes (T2D) and to reduce the risks of long-term diabetes-related complications [1, 2]. The American Diabetes Association (ADA) and the European Association for the Study of Diabetes (EASD) recommend a target hemoglobin A1c (HbA1c) value of less than $7.0 \%$ for adults with T2D, to be adjusted on the basis of patientspecific factors such as age, duration of diabetes, comorbidities, and vascular complications $[1,2]$. As T2D is a progressive disease, treatment recommendations generally advise starting with one or more oral antidiabetic agents (OADs) and progressing to basal insulin and/or other injectable medications, such as bolus (prandial) insulin or glucagon-like peptide 1 (GLP-1) receptor agonists, when diabetes control remains poor $[1,2]$.

Despite established treatment recommendations, research has shown that clinical inertia, or the failure to intensify treatment in T2D despite poor diabetes control, is a substantial problem in T2D management [3-9]. Clinical inertia is a well-documented barrier to insulin initiation, but there is also evidence of clinical inertia in post-basal insulin intensification in poorly controlled T2D, including failure to intensify and delays to intensification [8]. A meta-analysis of 16 randomized controlled trials of varying insulin treatment regimens in adults with T2D found that more than $60 \%$ of $\mathrm{T} 2 \mathrm{D}$ patients treated with basal insulin remained uncontrolled with HbA1c levels greater than 7\% [10]. Furthermore, patients' beliefs about diabetes and insulin, fear of side effects, and social stigma have also been shown to be a barrier to intensified treatment $[11,12]$.

Among T2D patients intensified to more complex treatment regimens, medication nonadherence and non-persistence are frequent challenges to effective treatment [13-15].
Adherence is generally defined as the extent to which a person follows the treatment regimen agreed upon with their healthcare provider (HCP), which may include diet, medication, and other lifestyle changes, while persistence refers to the length of time a person continues their treatment during a prescribed period [13]. A number of studies have shown that adherence to treatment regimens, including OADs and insulin, is quite low among T2D patients, though estimates vary depending on the treatment, how adherence is measured, and the population studied [13, 14, 16, 17]. Research has also found that more complex regimens are associated with decreased adherence [13, 14]. Treatment non-adherence in T2D has been associated with poor glycemic control and increased healthcare resource use $[13,16,18]$.

Currently, there is limited knowledge about the issues and challenges that patients with T2D treated with basal insulin experience when intensifying to more complex treatment regimens, such as basal-bolus insulin therapy. The purpose of this study was to investigate the experiences of adults with T2D who have been intensified from basal insulin to a basal-bolus insulin regimen, including challenges related to intensification, medication adherence issues, non-persistence, and healthcare resource use related to intensification.

\section{METHODS}

A web-based survey of adults diagnosed with T2D and currently treated with basal insulin was conducted in the UK and the USA from 2015 to 2016. Prior to commencement, the study received ethics approval from Copernicus Group Institutional Review Board (Tracking \# TBG1-15-737). All procedures followed were in accordance with the ethical standards of the responsible committee on human experimentation (institutional and national) and with the Helsinki Declaration of 1964, as revised in 2013. Informed consent was obtained from all respondents who participated in the study. 


\section{Survey Development}

The survey was developed on the basis of a qualitative analysis of data from concept elicitation focus group interviews with patients and individual interviews with physicians. The purpose of the concept elicitation interviews was to identify important concepts and issues related to complex treatment regimens in T2D from the patient and physician perspectives. A qualitative analysis, based on focus group data from a previous study of people with type 1 diabetes (T1D) or T2D and treated with basal-bolus insulin therapy, informed the survey development. The focus groups were conducted with 77 patients with T1D or T2D and treated with basal-bolus insulin therapy in Germany, the UK, and USA and are described elsewhere [19]. For this study, concept elicitation interviews were also conducted with 16 physicians, including general practitioners (GPs) and specialists (diabetologists/endocrinologists) in the UK ( $n=8 ; 4$ GPs and 4 specialists) and USA ( $n=8 ; 4$ GPs and 4 specialists) regarding their experiences with complex regimen treatments in T2D. Following survey item generation, cognitive debriefing interviews and usability testing were conducted with an additional 10 adults with T2D in the USA. The purpose of the cognitive debriefing interviews was to confirm that instructions and items were clear, relevant, and inoffensive and that appropriate recall periods were used. The usability testing was conducted to ensure that the survey structure and format were acceptable. The final survey included 116 questions and took approximately $35 \mathrm{~min}$ to complete.

\section{Participants}

Participants were recruited via proprietary databases used for research purposes that people previously opted to be included in, as well as opt-in social media communities that are disease specific, where participants can discuss diabetes. Potential respondents were required to complete a brief online screening survey to ensure eligibility for the study. To discourage potential misreporting of a diabetes diagnosis, participants were not aware that a diabetes diagnosis was required for survey participation when completing the screener. Respondents were asked at the beginning of the survey screener to indicate whether they had been diagnosed by an HCP with a number of different medical conditions, including acne, allergies, asthma, diabetes, migraines, and osteoporosis, and respondents were required to select diabetes to continue in the screener. The survey included recruitment targets by country, gender, and complex regimen experiences to ensure adequate sampling across differing demographic groups and to include people with differing complex regimen experiences.

Survey eligibility criteria included adults diagnosed with T2D at age 25 years or older, currently treated with a self-administered, fixed dose of basal insulin, and either (1) currently taking self-administered bolus insulin, (2) stopped bolus insulin or GLP-1 in the past year, or (3) refused to start bolus insulin in the past year despite HCP recommendation. If currently treated with bolus insulin, respondents had to calculate bolus dosage as recommended by the American Diabetes Association [1] (indicating "I calculate my dose and it sometimes changes"), rather than taking a fixed dose (indicating "I take the same amount every day"). Respondents were also required to report bolus adherence at least $90 \%$ of the time ("good adherers") or less than $80 \%$ of the time ("poor adherers"). In previous studies, an 80\% adherence rate has frequently been used as a cutoff for defining insulin adherence vs. nonadherence in patients with T2D $[14,16]$. The survey screener was designed to exclude respondents with $80-89 \%$ adherence to bolus insulin from the study to avoid a "gray zone" in which there may be overlap in the "good adherers" vs. "poor adherers" groups, but no respondents were actually excluded from the study solely because of falling into the $80-89 \%$ adherence range.

Exclusion criteria included use of a pump or inhaler for insulin administration $(n=332$ excluded), current use of a GLP-1 medication ( $n=710$ excluded) or premix insulin $(n=3828$ excluded), and current or previous use of Saxenda ${ }^{\circledR}$ (Novo Nordisk) (also a GLP-1 medication, 
but not FDA-approved to treat T2D; $n=9$ excluded). Respondents were excluded from the survey if their reasons for discontinuing bolus or GLP-1 in the past year suggested that the treatment was no longer prescribed, in which case discontinuation would not be considered non-persistence. These reasons included (1) HCP said medication was no longer needed; (2) I was able to control blood glucose through lifestyle changes and no longer needed; or (3) I don't remember/no reason given (total $n=142$ excluded for these reasons). Respondents were also excluded if medication was "too expensive" was the only reason given for discontinuing bolus or GLP-1 ( $n=9$ excluded).

\section{Data Analysis}

Given the study's focus on patient experiences with basal-bolus insulin therapy, the final analysis sample was restricted to respondents who were currently treated with basal-bolus insulin therapy or who had discontinued bolus insulin in the previous 12 months but were currently treated with basal insulin. Respondents were divided into three groups for analysis: (1) "good adherers" to bolus insulin (at least 90\% adherent); (2) "poor adherers" to bolus insulin (less than 80\% adherent); and (3) "stopped bolus" insulin in the past 12 months (but continued to be treated with basal insulin). Descriptive analyses included frequencies, percentages, means, and standard deviations. Bivariate crosstabulations were used to compare categorical variables across the analysis groups. Chi-square tests of significance were used to assess whether associations were statistically significant. Analysis of variance (ANOVA) was used for comparison of means across analysis groups. Graphical methods (histograms) were used to confirm that continuous variables approximated a normal distribution prior to conducting ANOVA. A post hoc Bonferroni multiple-comparison test was used to assess significant differences between two analysis groups following ANOVA. Statistical significance was set at $p<0.05$. All data were analyzed using Stata/SE, version 14 [20].

\section{RESULTS}

\section{Sample Descriptive Statistics}

A total of 657 participants completed the survey. Respondents who did not have current or recent basal-bolus treatment experience, including those who refused to intensify to a basal-bolus regimen in the past 12 months $(n=140)$ and respondents who discontinued GLP-1 in the past 12 months $(n=119)$, were excluded from the analysis. The final analysis sample was $n=398$ (UK, $n=203$; USA, $n=195$ ). Descriptive and health characteristics for the analysis sample by basal-bolus analysis group are presented in Table 1 . Average respondent age was 47.8 years, and $59.6 \%$ of respondents were female. The majority of respondents were employed $(66.8 \%)$, and $63.8 \%$ of respondents had a college or technical degree. Average age at T2D diagnosis was 39.5 years, and $63.1 \%$ of respondents indicated that their diabetes was "well" or "very well" controlled. A total of $43.5 \%$ of respondents reported being in "very good" or "excellent" general health.

As shown in Table 1, there were some significant differences in diabetes and health characteristics among the basal-bolus analysis groups. Basal-bolus adherent respondents were older, on average, (50.7 years) compared to the basal-bolus non-adherent (46.5 years) and stopped bolus (46.4 years) groups $(p<0.001)$. A greater percentage of respondents in the basal-bolus nonadherent group was female $(80.0 \%)$ compared to the basal-bolus adherent $(53.9 \%)$ and stopped bolus $(45.7 \%)$ groups $(p<0.001)$. A larger proportion of respondents in the basal-bolus nonadherent analysis group were employed (90.0\%) compared to the basal-bolus adherent (53.1\%) and the stopped bolus (57.9\%) groups $(p<0.001)$. Further, basal-bolus adherent respondents were less likely to self-report that their diabetes is "well" or "very well" controlled and that they are in "very good" or "excellent" health compared to the non-adherent and stopped bolus groups. Compared to the basalbolus non-adherent and stopped bolus groups, respondents who were basal-bolus adherent also self-reported more diabetes-related medical 
Table 1 Demographic and diabetes/health characteristics

\begin{tabular}{|c|c|c|c|c|c|c|}
\hline & & $\begin{array}{l}\text { Basal-bolus } \\
\text { adherent } \\
(n=128)\end{array}$ & $\begin{array}{l}\text { Basal-bolus } \\
\text { non-adherent } \\
(n=130)\end{array}$ & $\begin{array}{l}\text { Stopped } \\
\text { bolus } \\
(n=140)\end{array}$ & $\begin{array}{l}\text { Total } \\
(n=398)\end{array}$ & $p$ \\
\hline $\operatorname{Age}^{a, b_{* * *}}$ & Mean (SD) & $50.7(11.0)$ & $46.5(7.9)$ & $46.4(8.3)$ & $47.8(9.3)$ & $<0.001$ \\
\hline Gender $^{\mathrm{c}_{* * *}}$ & $n(\%)$ female & $69(53.9)$ & $104(80.0)$ & $64(45.7)$ & $237(59.6)$ & $<0.001$ \\
\hline Marital status ${ }^{\mathrm{c} * *}$ & $\begin{array}{l}n(\%) \text { married/ } \\
\text { partnered }\end{array}$ & $88(68.8)$ & $66(50.8)$ & $91(65.0)$ & $245(61.6)$ & 0.007 \\
\hline Employed $^{\mathrm{b}_{* * *}}$ & $n(\%)$ yes & $68(53.1)$ & $117(90.0)$ & $81(57.9)$ & $266(66.8)$ & $<0.001$ \\
\hline College/vocational degree ${ }^{\mathrm{c}_{* *}}$ & $n(\%)$ yes & $81(63.3)$ & $97(74.6)$ & $76(54.3)$ & $254(63.8)$ & 0.002 \\
\hline \multirow[t]{2}{*}{ Country $^{c}$} & $n(\%) \mathrm{UK}$ & $68(53.1)$ & $65(50.0)$ & $70(50.0)$ & $203(51.0)$ & 0.844 \\
\hline & $n(\%)$ USA & $60(46.9)$ & $65(50.0)$ & $70(50.0)$ & $195(49.0)$ & \\
\hline Age diagnosed with $\mathrm{T} 2 \mathrm{D}^{\mathrm{a}, \mathrm{d} * * *}$ & Mean $(\mathrm{SD})$ years & $40.6(8.3)$ & $41.0(6.6)$ & $37.0(6.0)$ & $39.5(7.2)$ & $<0.001$ \\
\hline \multirow[t]{2}{*}{ Insulin method ${ }^{\mathrm{c} * * *}$} & $\begin{array}{l}n(\%) \text { needle/ } \\
\text { syringe }\end{array}$ & $39(30.5)$ & $9(6.9)$ & $56(40.0)$ & $104(26.1)$ & $<0.001$ \\
\hline & $n(\%)$ insulin pen & $89(69.5)$ & $121(93.1)$ & $84(60.0)$ & $294(73.9)$ & \\
\hline Diabetes control ${ }^{\mathrm{c} * * *}$ & $\begin{array}{l}n(\%) \text { well/very } \\
\text { well controlled }\end{array}$ & $60(46.9)$ & $87(66.9)$ & $104(74.3)$ & $251(63.1)$ & $<0.001$ \\
\hline General health $^{\mathrm{c}_{* * *}}$ & $\begin{array}{l}n(\%) \text { very good/ } \\
\text { excellent }\end{array}$ & $28(21.9)$ & $89(68.5)$ & $56(40.0)$ & $173(43.5)$ & $<0.001$ \\
\hline \multicolumn{7}{|c|}{ Diabetes-related medical complications (self-reported) ${ }^{c}$} \\
\hline High blood pressure ${ }^{* * *}$ & $n(\%)$ yes & $61(47.7)$ & $21(16.2)$ & $15(10.7)$ & $97(24.4)$ & $<0.001$ \\
\hline Eye problems*** & & $33(25.8)$ & $22(16.9)$ & $9(6.4)$ & $64(16.1)$ & $<0.001$ \\
\hline Nerve damage* & & $23(18.0)$ & $15(11.5)$ & $10(7.1)$ & $48(12.1)$ & 0.024 \\
\hline Heart/cardiovascular problems & & $11(8.6)$ & $7(5.4)$ & $4(2.9)$ & $22(5.5)$ & 0.121 \\
\hline Kidney (renal) disease ${ }^{* * *}$ & & $27(21.1)$ & $4(3.1)$ & $0(0.0)$ & $31(7.8)$ & $<0.001$ \\
\hline Amputations/other** & & $12(9.4)$ & $4(3.1)$ & $2(1.4)$ & $18(4.5)$ & 0.005 \\
\hline No complications ${ }^{* * *}$ & & $45(35.2)$ & $74(56.9)$ & $115(82.1)$ & $234(58.8)$ & $<0.001$ \\
\hline
\end{tabular}

$S D$ standard deviation, $T 2 D$ type 2 diabetes

${ }^{a}$ ANOVA (analysis of variance) test indicates significant differences among analysis groups, ${ }^{* * *} p<0.001$. ANOVA analysis of variance

b A post hoc Bonferroni multiple-comparison test indicated significant differences between the basal-bolus adherent and non-adherent groups $(p=0.001)$ and between the basal-bolus adherent and stopped bolus groups $(p<0.001)$

${ }^{c}$ Chi-square test indicates significant differences among analysis groups: ${ }^{*} p<0.05 ;{ }^{* *} p<0.01 ;{ }^{* * *} p<0.001$

${ }^{\mathrm{d}}$ A post hoc Bonferroni multiple-comparison test indicated significant differences between the basal-bolus adherent and stopped bolus groups $(p<0.001)$ and between the basal-bolus non-adherent and stopped bolus groups $(p<0.001)$

complications, including high blood pressure, eye problems, nerve damage, and kidney disease. These differences were not explained by group age differences, as patterns were similar when restricting analyses to younger respondents (less than the median age of 48 years). 


\section{Intensifying from Basal Insulin to a Basal- Bolus Regimen}

Respondent experiences with intensifying from basal insulin to a basal-bolus regimen, including discussions with HCPs and initial education and training, are shown in Table 2. About half of respondents $(52.5 \%)$ reported discussing bolus insulin with their HCPs one time before agreeing to initiate bolus insulin, while $22.6 \%$ reported discussing bolus two times, and $24.9 \%$ discussed bolus three or more times. Basal-bolus non-adherent respondents were most likely to report having only one discussion with their HCP (73.1\%) before starting bolus insulin followed by the basal-bolus adherent (52.3\%) and stopped bolus $(33.6 \%)$ groups $(p<0.001)$.

Respondents' reports of what they discussed when their HCPs first suggested intensification with bolus insulin are shown in Fig. 1. Compared to those in the basal-bolus adherent and stopped bolus groups, the basal-bolus non-adherent respondents were significantly less likely to report discussing how to take bolus insulin and potential side effects with their HCPs when bolus insulin was first suggested, including the number of blood glucose tests needed per day, the number of bolus injections required per day, the need to calculate bolus doses, the type of injection needed, possible hypoglycemia or hyperglycemia, the need to regulate food in relation to bolus insulin, and possible weight gain. Half of respondents in the non-adherent group $(50.8 \%)$ reported that they discussed "none of the above," compared to $17.2 \%$ of the adherent group and $3.6 \%$ of the stopped bolus group $(p<0.001)$.

A little more than half of respondents $(54.5 \%)$ reported having some type of training, including HCP visits or group classes, to learn how to take bolus insulin correctly and/or to manage possible side effects. Basal-bolus non-

Table 2 Discussions with HCPs and education/training when intensifying to a basal-bolus insulin regimen

\begin{tabular}{llll}
\hline Basal-bolus adherent & Basal-bolus non-adherent & Stopped bolus & Total \\
$(n=128)$ & $(n=130)$ & $(n=398)$ & $140)$
\end{tabular}

Discussions with HCPs regarding bolus insulin

Number of times discussed bolus insulin with HCP before agreed to start taking it, $n(\%)^{* * *}$

$\begin{array}{llllr}1 \text { time } & 67(52.3) & 95(73.1) & 47(33.6) & 209(52.5) \\ 2 \text { times } & 32(25.0) & 25(19.2) & 33(23.6) & 90(22.6) \\ 3 \text { or more } & 29(22.7) & 10(7.7) & 60(42.9) & 99(24.9)\end{array}$

times

Education/training when intensifying with bolus insulin

Had HCP visits or group classes to learn how to take bolus correctly and/or manage possible side effects***
$n(\%)$ yes
79 (61.7)
$33(25.4)$
$105(75.0)$
$217(54.5)$

Total training time, $n(\%)^{* * *}$

$\begin{array}{llccc}\begin{array}{l}\text { No training } \\ \text { time }\end{array} & 49(38.3) & 97(74.6) & 35(25.0) & 181(45.5) \\ <1 \mathrm{~h} & 25(19.5) & 7(5.4) & 32(22.9) & 64(16.1) \\ 1-2 \mathrm{~h} & 29(22.7) & 11(8.5) & 35(25.0) & 75(18.8) \\ >2 \mathrm{~h} & 25(19.5) & 15(11.5) & 38(27.1) & 78(19.6)\end{array}$

Chi-square tests indicate significant differences among analysis groups: ${ }^{* * *} p<0.001$

$H C P$ healthcare provider 


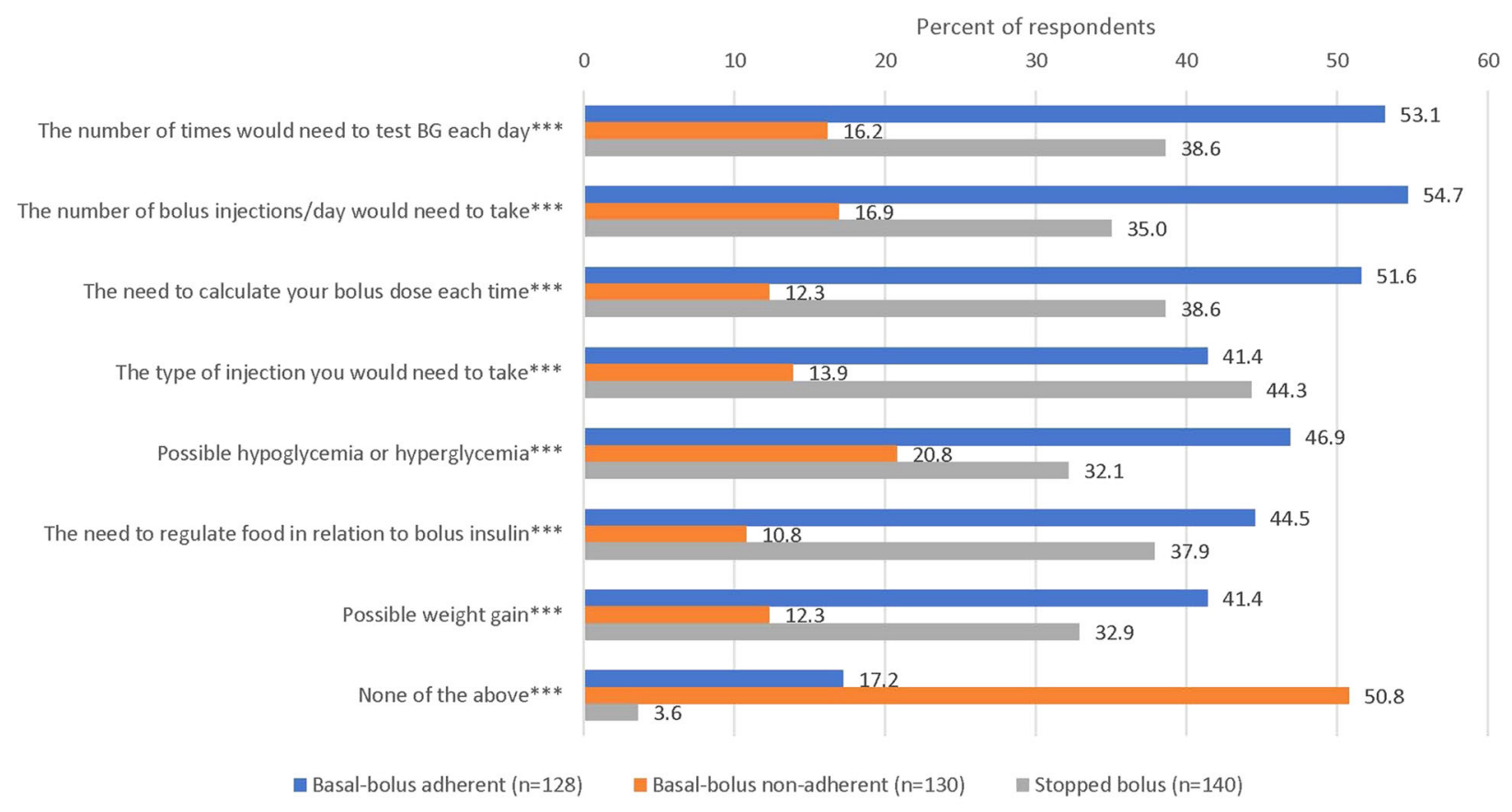

Fig. 1 When your HCP first suggested that you start taking bolus insulin, which of the following was discussed? Responses not mutually exclusive. Chi-square tests indicate significant differences among analysis groups $\left({ }^{* * *} p<0.001\right)$. HCP healthcare provider, BG blood glucose

adherent respondents were significantly less likely to report having any training $(25.4 \%)$ compared to the basal-bolus adherent $(61.7 \%)$ or the stopped bolus $(75.0 \%)$ groups $(p<0.001)$.

\section{Challenges Associated with Basal-Bolus Insulin Regimen}

Respondents also reported difficulties and worries related to intensification to a basal-bolus regimen and taking bolus insulin. Among all respondents, $52.0 \%$ reported that it was "difficult" or "extremely difficult" to take two or more injections per day, and $56.5 \%$ indicated that it was "difficult" or "extremely difficult" to calculate the correct amount of bolus insulin to take. Respondents in the basal-bolus non-adherent group reported more difficulties associated with bolus insulin compared to the basalbolus adherent and stopped bolus groups. A total of $76.9 \%$ of basal-bolus non-adherent respondents reported that it was "difficult" or "extremely difficult" to take two or more injections per day compared to $28.9 \%$ among basalbolus adherent and 50.0\% among stopped bolus respondents $(p<0.001)$. Similarly, $82.3 \%$ of basal-bolus non-adherent respondents indicated that it was "difficult" or "extremely difficult" to calculate the correct amount of bolus insulin to take, compared to $32.0 \%$ among the basal-bolus adherent group and 55.0\% among the stopped bolus group $(p<0.001)$.

Additionally, $45.3 \%$ of respondents reported that they worried whether they were taking bolus insulin correctly "often" or "always." Significant differences in worries were observed among basal-bolus analysis groups. The basalbolus non-adherent respondents were most likely to report being "often" or "always" worried about whether they were taking bolus insulin correctly $(69.2 \%)$ compared to $48.4 \%$ among the stopped bolus group and $18.0 \%$ among the basal-bolus adherent group, and differences were statistically significant $(p<0.001)$. 


\section{Bolus Insulin Non-Persistence}

Respondents in the stopped bolus group, who discontinued bolus insulin within the past 12 months but continued to take basal insulin, were asked to report on their reasons for bolus insulin non-persistence (Fig. 2, responses not mutually exclusive). The most frequently reported reasons for discontinuing bolus insulin were associated with the complicated nature of the basal-bolus regimen, including too complicated to calculate bolus insulin doses $(25.7 \%)$, too complicated to regulate food in relation to bolus insulin $(20.7 \%)$, and too complicated to keep track of taking two different insulins (18.6\%). Other important reasons included weight gain (17.9\%), not confident taking bolus insulin correctly $(17.1 \%)$, too many injections to take each day (16.4\%), too complicated to schedule bolus insulin doses (15.0\%), and low blood sugar/hypoglycemia (13.6\%).

Respondents who stopped bolus also reported on their feelings regarding their decision to discontinue bolus insulin (Table 3). When asked whether discontinuing bolus insulin was the right decision, $66.4 \%(n=93)$ of respondents reported "yes," while $10.0 \%(n=14)$ indicated "no" and 23.6\% $(n=33)$ were "unsure". Among respondents who thought that discontinuing bolus insulin was the right decision $(n=93)$, the most frequently reported reasons for this were "I was having trouble calculating my dose correctly" (40.9\%), "I was having trouble remembering to take it at the right time" (35.5\%), "My schedule is too irregular to use it" (25.8\%), and "I don't think my diabetes is serious enough for me to need it" (23.7\%). Among respondents who indicated that discontinuing bolus insulin was the wrong decision or who were unsure $(n=47)$, the most frequently reported reasons given were "I don't think I took long enough to see results" (46.8\%), "My diabetes control has gotten worse" (38.3\%), "I feel guilty about my decision" (25.5\%), "My HCP was displeased about my decision" (21.3\%), and "I think my diabetes is serious enough for me to need it" (19.2\%).

Respondents who stopped bolus insulin also self-reported changes that they made to their diabetes management after discontinuing bolus insulin (Fig. 3). The most frequently reported changes were "I improved my diet" (51.4\%), "I increased my exercise" (35.0\%), "I increased my basal dose" (24.3\%), "I lost weight" (20.7\%), and "I did not make any changes" (20.0\%). Fewer respondents reported increasing their oral

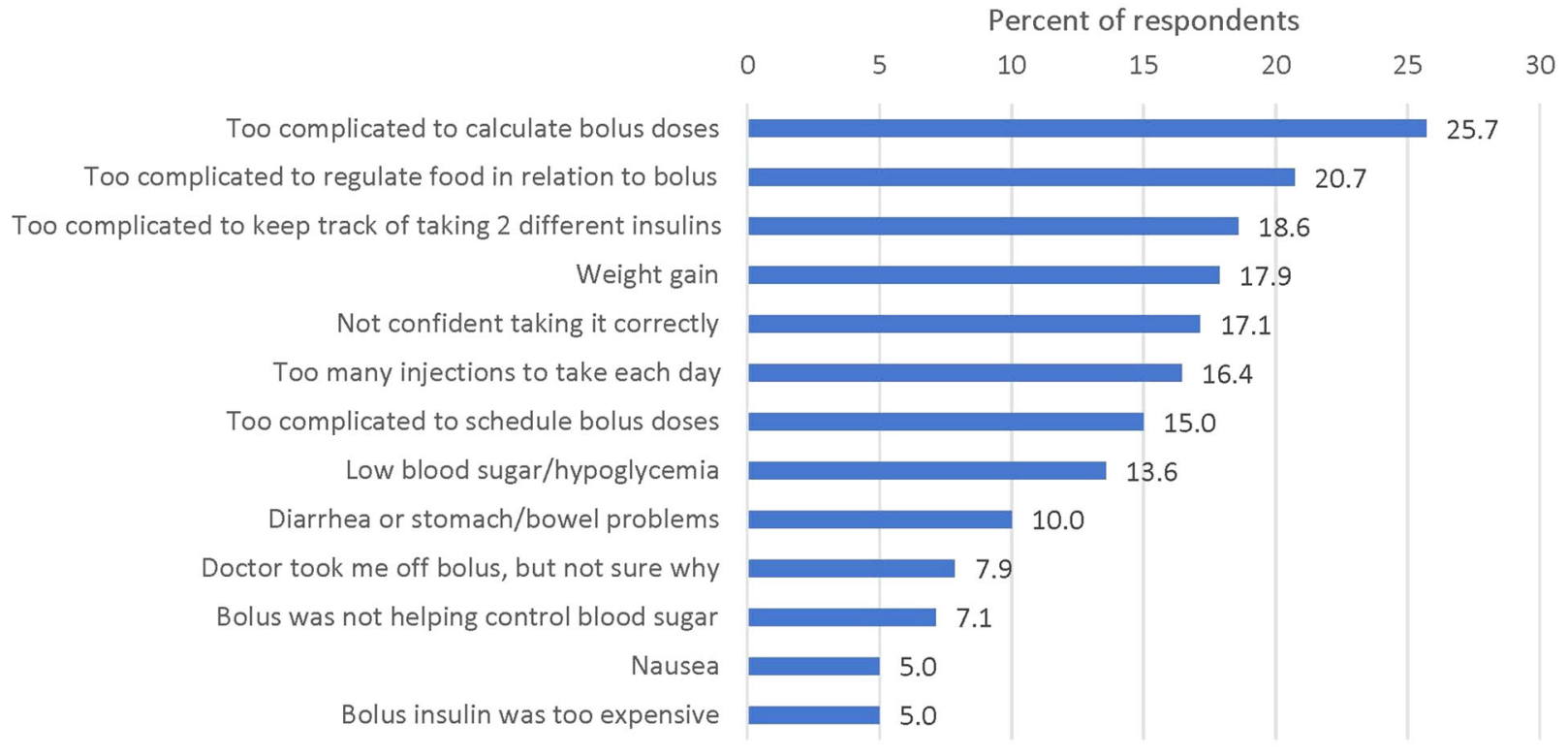

Fig. 2 Reasons for basal-bolus non-persistence. Responses not mutually exclusive, $n=140$ 
Table 3 Feelings regarding the decision to discontinue bolus insulin

n $\%$

Do you feel that stopping bolus insulin was the right decision? ? $^{\mathrm{a}}$

Yes

No

$14 \quad 10.0$

Unsure

$33 \quad 23.6$

Why was stopping bolus the right decision for you? ${ }^{\mathrm{b}}$

$\begin{array}{ll}\text { I was having trouble calculating my dose correctly } & 38 \quad 40.9\end{array}$

I was having trouble remembering to take it at the right time $\quad 33 \quad 35.5$

My schedule is too irregular to use it $\quad \begin{array}{ll}24 & 25.8\end{array}$

I don't think my diabetes is serious enough for me to need it $\quad 22 \quad 23.7$

I think I have fewer side effects now $\quad 13 \quad 14.0$

I think I am more adherent/better at taking my basal insulin the way I am supposed to now that I no longer $6 \quad 6.5$ take it

Why was stopping bolus the wrong decision?/Why are you unsure?

$\begin{array}{ll}\text { I don't think I took long enough to see results } & 22 \quad 46.8\end{array}$

$\begin{array}{lr}\text { My diabetes control has gotten worse } & 18 \quad 38.3\end{array}$

I feel guilty about my decision $\quad 1225.5$

My HCP was displeased about my decision $\quad \begin{array}{ll}10 & 21.3\end{array}$

I think my diabetes is serious enough for me to need it $\quad 919.2$

I think I have more side effects now $\quad \begin{array}{ll}6 & 12.8\end{array}$

$\begin{array}{lll}\text { Other } & 3 & 6.4\end{array}$

\begin{tabular}{lll} 
My diabetes is out of control now & 1 & 2.1 \\
\hline
\end{tabular}

a $n=140$

${ }^{\mathrm{b}}$ Responses not mutually exclusive; analysis restricted to respondents who reported that stopping bolus insulin was the right decision, $n=93$

${ }^{c}$ Responses not mutually exclusive; analysis restricted to respondents who reported that stopping bolus insulin was the wrong decision or were unsure, $n=47$

diabetes medication dose $(7.9 \%)$ or adding a new diabetes medication to basal insulin $(0.7 \%)$ after discontinuing bolus insulin.

\section{Basal-Bolus Regimen and Healthcare Resource Use}

All respondents reported on their healthcare resource use related to diabetes, which is shown by analysis group in Table 4 . Respondents who stopped bolus insulin reported the greatest number of HCP visits related to diabetes in the past 6 months (2.8 visits), followed by the basalbolus adherent (2.1 visits) and the basal-bolus non-adherent $(1.2$ visits $)$ groups $(p<0.001)$. The stopped bolus group also reported a significantly greater number of calls to their HCPs related to diabetes in the past 6 months (1.9 calls) compared to the basal-bolus adherent (0.7 calls) and basal-bolus non-adherent (0.7 calls) 


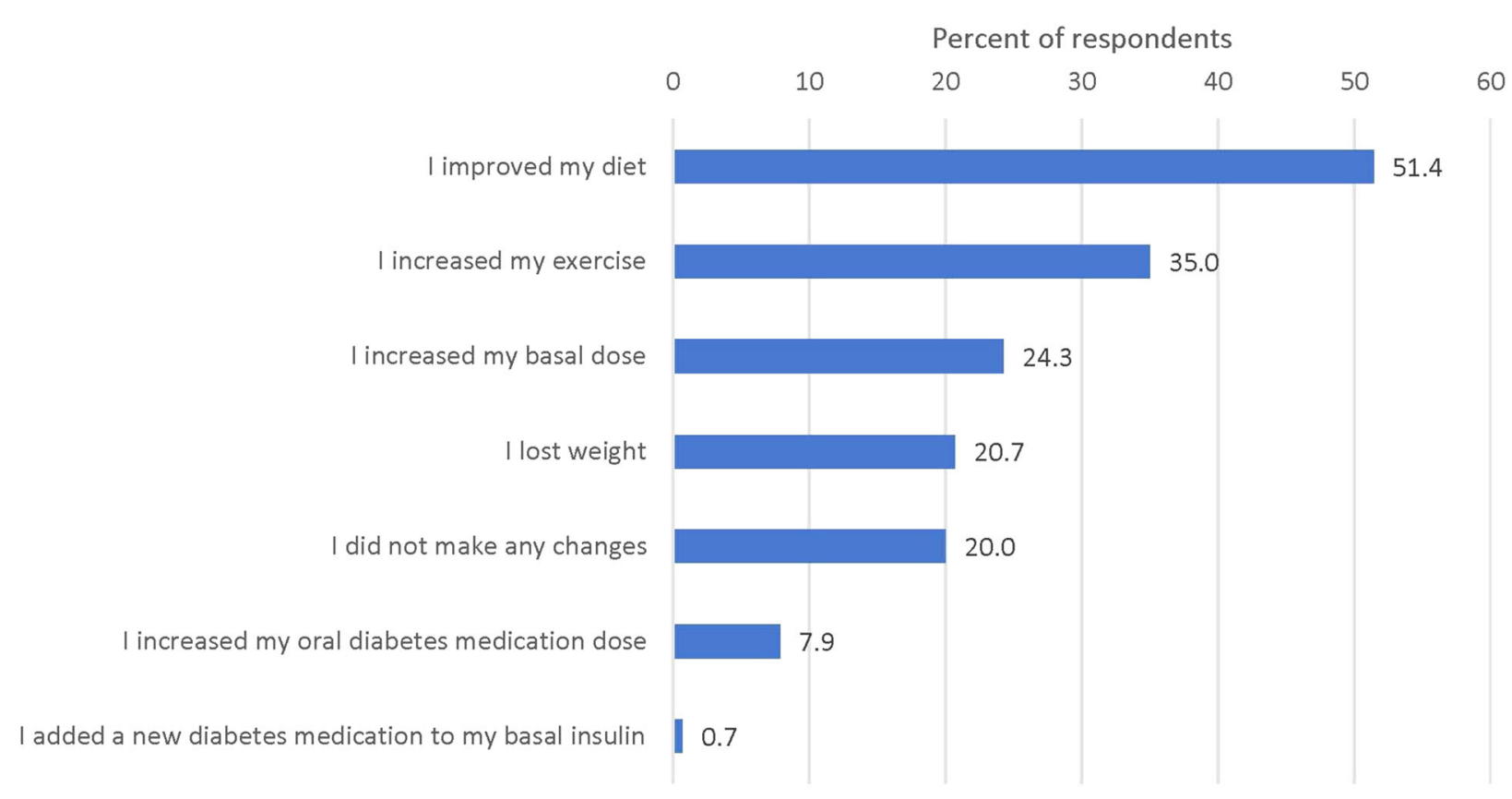

Fig. 3 What changes did you make to your diabetes management when you stopped taking your bolus insulin? Responses not mutually exclusive, $n=140$

groups $(p<0.001)$. Similar patterns were evident for both HCP visits and HCP calls specific to problems or issues with diabetes. Emails to HCPs related to diabetes in general or to problems/issues with diabetes did not differ significantly among the analysis groups.

\section{DISCUSSION}

This study highlights some of the challenges people with T2D experience with their basalbolus regimens and adds to previous research on insulin therapy and treatment adherence in T2D. The analyses showed an association between some patient demographic characteristics and basal-bolus adherence. Respondents who were non-adherent to their basal-bolus regimens were more likely to be employed compared to those who were more adherent, which is consistent with research on diabetes medication adherence in other countries $[17,21]$. Given the complexity and importance of timing for bolus dosing, it may be that employed people have more difficulty scheduling and adhering to their basal-bolus regimens. Additionally, the study found that non- adherent respondents were younger, on average, compared to the adherent, which is also in line with prior research $[17,21]$.

The study also provided insights into the people with T2D who stopped basal-bolus. The most frequently reported reasons for bolus insulin non-persistence were all related to the complexity of the basal-bolus regimen (too complicated to calculate bolus doses; too complicated to regulate food in relation to bolus; too complicated to keep track of taking two different insulins). Non-adherent respondents and those who stopped bolus insulin also reported more difficulties and worries about whether they were taking bolus insulin correctly compared to those who were basal-bolus adherent.

Further, the findings suggest that fewer discussions with HCPs and less patient education are associated with basal-bolus non-adherence. Basal-bolus non-adherent respondents reported fewer discussions with their HCPs about bolus insulin before agreeing to start basal-bolus therapy and were less likely to report having patient education when starting bolus insulin compared to those who were basal-bolus adherent. This is in line with previous research, 
Table 4 Healthcare resource use by basal-bolus regimen group

\begin{tabular}{|c|c|c|c|c|c|}
\hline & $\begin{array}{l}\text { Basal-bolus } \\
\text { adherent } \\
(n=128)\end{array}$ & $\begin{array}{l}\text { Basal-bolus non- } \\
\text { adherent } \\
(n=130)\end{array}$ & $\begin{array}{l}\text { Stopped } \\
\text { bolus } \\
(n=140)\end{array}$ & $\begin{array}{l}\text { Total } \\
(n=398)\end{array}$ & $p$ value \\
\hline $\begin{array}{l}\text { Number of HCP visits related to diabetes in } \\
\text { the past } 6 \text { months, mean }(S D)^{a * * *}\end{array}$ & $2.1(2.7)$ & $1.2(2.3)$ & $2.8(2.5)$ & $2.0(2.6)$ & $<0.001$ \\
\hline $\begin{array}{l}\text { Number of HCP visits for problems/issues } \\
\text { with diabetes in past } 6 \text { months, mean } \\
(\mathrm{SD})^{\mathrm{b}_{* * *}}\end{array}$ & $1.1(2.4)$ & $0.4(1.0)$ & $1.5(1.7)$ & $1.0(1.8)$ & $<0.001$ \\
\hline $\begin{array}{l}\text { Number of calls to HCP in past } 6 \text { months } \\
\text { related to diabetes, mean }(S D)^{c_{* * *}}\end{array}$ & $0.7(1.7)$ & $0.7(1.8)$ & $1.9(2.4)$ & $1.1(2.1)$ & $<0.001$ \\
\hline $\begin{array}{l}\text { Number of calls to HCP in past } 6 \text { months for } \\
\text { problems/issues with diabetes, mean } \\
(\mathrm{SD})^{\mathrm{c} * * *}\end{array}$ & $0.5(1.4)$ & $0.4(1.5)$ & $1.3(2.0)$ & $0.7(1.7)$ & $<0.001$ \\
\hline $\begin{array}{l}\text { Number of emails to HCP in past } 6 \text { months } \\
\text { related to diabetes, mean }(\mathrm{SD})\end{array}$ & $0.4(1.4)$ & $0.4(1.2)$ & $0.3(1.0)$ & $0.4(1.2)$ & 0.597 \\
\hline $\begin{array}{l}\text { Number of emails to HCP in past } 6 \text { months } \\
\text { for problems/issues with diabetes, mean } \\
\text { (SD) }\end{array}$ & $0.3(0.9)$ & $0.2(0.6)$ & $0.2(0.7)$ & $0.2(0.7)$ & 0.668 \\
\hline
\end{tabular}

ANOVA test indicates significant differences among analysis groups: ${ }^{* * *} p<0.001$

$H C P$ healthcare provider, $S D$ standard deviation, $A N O V A$ analysis of variance

a A post hoc Bonferroni multiple-comparison test indicated significant differences between the basal-bolus adherent and non-adherent groups $(p=0.013)$, and between the basal-bolus adherent and stopped bolus groups $(p=0.036)$, and between the basal-bolus non-adherent and stopped bolus groups $(p<0.001)$

b A post hoc Bonferroni multiple-comparison test indicated significant differences between the basal-bolus adherent and non-adherent groups $(p=0.006)$ and between the basal-bolus non-adherent and stopped bolus groups $(p<0.001)$

${ }^{c}$ A post hoc Bonferroni multiple-comparison test indicated significant differences between the basal-bolus adherent and stopped bolus groups $(p<0.001)$ and between the basal-bolus non-adherent and stopped bolus groups $(p<0.001)$

which has shown that more collaborative relationships with HCPs are associated with greater diabetes treatment adherence [17, 22].

Finally, the study found that basal-bolus non-persistence was associated with greater healthcare resource use. Respondents who stopped bolus insulin within the past 12 months reported greater healthcare resource use related to diabetes, including HCP visits and phone calls, compared to respondents who were basal-bolus adherent or basal-bolus non-adherent. The study also found that the basal-bolus adherent were more likely to have HCP visits related to diabetes, as well as HCP visits for problems or issues with diabetes, compared to the non-adherent. Previous research has found that diabetes treatment non-adherence is associated with greater healthcare resource use costs and more frequent hospitalizations and emergency room visits, but also with reduced costs for medication and outpatient care [18]. Thus, it may be that patients who are more adherent to basal-bolus are more likely to visit their HCPs for regular diabetes care compared to the nonadherent and are thus more likely to avoid expensive inpatient care and emergency room visits.

The study findings have implications for clinicians, patients, and payers. Patient education and training when intensifying treatment regimens may improve patient confidence and adherence to basal-bolus insulin treatment 
regimens for some T2D patients. Physician education may also raise awareness of some of the risk factors for patient non-adherence and the challenges patients face when intensifying treatment. Less complex post-basal insulin treatment regimens could improve adherence and persistence with intensified regimens among people with T2D [13]. Previous research has found that less complex diabetes treatment regimens are associated with increased medication adherence, which is associated with improved glycemic control and reduced healthcare resource use costs [13, 14, 18].

When interpreting study results, several limitations should be recognized. As the study relies on a web-based survey, there is the potential for selection bias. Although recruitment targets included differing demographic groups, it is possible that some groups were underrepresented. The basal-bolus non-adherent group was $80.0 \%$ female. It is unclear why respondents in this group were predominantly female and how this may have affected the results. Previous research has found that men over-report glaucoma medication adherence in their self-reports compared to adherence timing data collected from electronic monitors [23]. It is possible that there are gender differences in self-reported adherence to insulin, though additional research is warranted. As all data were self-reported, there is also the potential for recall bias. Particularly for the stopped bolus group, respondents' experiences with bolus insulin may be subject to greater recall bias as the length of time from bolus discontinuation increases. Further, there may be some limitations in the generalizability of results due to the inclusion and exclusion criteria and the focus on patients residing in the UK and the USA. Healthcare systems and culture may affect patients' experiences with complex treatment regimens. Finally, given the cross-sectional nature of the study, causal interpretations of the results cannot be made.

\section{CONCLUSION}

A better understanding of the issues and challenges associated with complex insulin treatments in T2D may help physicians and patients address some of the barriers to treatment intensification, adherence, and persistence, as well as improve diabetes control and reduce healthcare resource use. The findings show that the complex nature of the basal-bolus insulin regimen contributes to the difficulties patients experience with the regimen and to non-persistence. The results also suggest, however, that patient education and more collaborative patient-HCP relationships may better equip patients to manage these treatment complexities and challenges. Additionally, less complex treatment regimen options may be an optimal solution for some patients. Future research might explore possible cross-country differences in the challenges and experiences T2D patients have with complex treatment regimens.

\section{ACKNOWLEDGMENTS}

The authors would like to thank the participants of the study for their time and effort in completing the survey. The authors would also like to acknowledge Sarah Eggert for her contributions, including review of results and manuscript drafts.

Funding. This study and associated article processing charges were supported by Novo Nordisk A/S. All authors had full access to all of the data in this study and take complete responsibility for the integrity of the data and accuracy of the data analysis.

Editorial Assistance. Jane Beck of The Brod Group provided editorial assistance, which was included in the study support provided by Novo Nordisk A/S.

Authorship. All named authors meet the International Committee of Medical Journal Editors (ICMJE) criteria for authorship for this manuscript, take responsibility for the integrity of the work as a whole, and have given final approval to the version to be published. 
Disclosures. Kathryn M. Pfeiffer is a paid consultant to the pharmaceutical industry, including Novo Nordisk. Amaury Basse is an employee of Novo Nordisk A/S. Xin Ying Lee is an employee of Novo Nordisk A/S. Laura Tesler Waldman is a paid consultant to the pharmaceutical industry, including Novo Nordisk.

Compliance with Ethics Guidelines. Prior to commencement, the study received ethics approval from Copernicus Group Institutional Review Board (Tracking \# TBG1-15-737). All procedures followed were in accordance with the ethical standards of the responsible committee on human experimentation (institutional and national) and with the Helsinki Declaration of 1964, as revised in 2013. Informed consent was obtained from all respondents who participated in the study.

Data Availability. The subject level analysis dataset for the research presented in the publication is available from the corresponding author on reasonable request.

Open Access. This article is distributed under the terms of the Creative Commons Attribution-NonCommercial 4.0 International License (http://creativecommons.org/licenses/ by-nc/4.0/), which permits any noncommercial use, distribution, and reproduction in any medium, provided you give appropriate credit to the original author(s) and the source, provide a link to the Creative Commons license, and indicate if changes were made.

\section{REFERENCES}

1. American Diabetes Association. Standards of medical care in diabetes-2015. Diabetes Care. 2015;38(Suppl 1):S1-93.

2. Inzucchi SE, Bergenstal RM, Buse JB, et al. Management of hyperglycemia in type 2 diabetes, 2015: a patient-centered approach: update to a position statement of the American Diabetes Association and the European Association for the Study of Diabetes. Diabetes Care. 2015;38(1):140-9.
3. Lovre D, Fonseca V. Benefits of timely basal insulin control in patients with type 2 diabetes. J Diabetes Complications. 2015;29(2):295-301.

4. Blak BT, Smith HT, Hards M, Maguire A, Gimeno V. A retrospective database study of insulin initiation in patients with type 2 diabetes in UK primary care. Diabet Med. 2012;29(8):e191-8.

5. Dale J, Martin S, Gadsby R. Insulin initiation in primary care for patients with type 2 diabetes: 3-year follow-up study. Prim Care Diabetes. 2010;4(2):85-9.

6. Calvert MJ, McManus RJ, Freemantle N. Management of type 2 diabetes with multiple oral hypoglycaemic agents or insulin in primary care: retrospective cohort study. $\mathrm{Br} \mathrm{J}$ Gen Pract. 2007;57(539):455-60.

7. Nichols GA, Koo YH, Shah SN. Delay of insulin addition to oral combination therapy despite inadequate glycemic control: delay of insulin therapy. J Gen Intern Med. 2007;22(4):453-8.

8. Khunti K, Nikolajsen A, Thorsted BL, Andersen M, Davies MJ, Paul SK. Clinical inertia with regard to intensifying therapy in people with type 2 diabetes treated with basal insulin. Diabetes Obes Metab. 2016;18(4):401-9.

9. Khunti K, Wolden ML, Thorsted BL, Andersen M, Davies MJ. Clinical inertia in people with type 2 diabetes: a retrospective cohort study of more than 80,000 people. Diabetes Care. 2013;36(11):3411-7.

10. Giugliano D, Maiorino MI, Bellastella G, Chiodini $\mathrm{P}$, Ceriello A, Esposito K. Efficacy of insulin analogs in achieving the hemoglobin A1c target of $<7 \%$ in type 2 diabetes: meta-analysis of randomized controlled trials. Diabetes Care. 2011;34(2):510-7.

11. Brod M, Kongso JH, Lessard S, Christensen TL. Psychological insulin resistance: patient beliefs and implications for diabetes management. Qual Life Res. 2009;18(1):23-32.

12. Nam S, Chesla C, Stotts NA, Kroon L, Janson SL. Factors associated with psychological insulin resistance in individuals with type 2 diabetes. Diabetes Care. 2010;33(8):1747-9.

13. Garcia-Perez LE, Alvarez M, Dilla T, Gil-Guillen V, Orozco-Beltran D. Adherence to therapies in patients with type 2 diabetes. Diabetes Ther. 2013;4(2):175-94.

14. He $\mathrm{X}$, Chen $\mathrm{L}$, Wang $\mathrm{K}, \mathrm{Wu} \mathrm{H}$, Wu J. Insulin adherence and persistence among Chinese patients with type 2 diabetes: a retrospective database analysis. Patient Prefer Adherence. 2017;11:237. 
15. Cramer JA. A systematic review of adherence with medications for diabetes. Diabetes Care. 2004;27(5):1218-24.

16. Donnelly LA, Morris AD, Evans JM, DARTS/MEMO collaboration. Adherence to insulin and its association with glycaemic control in patients with type 2 diabetes. QJM. 2007;100(6):345-50.

17. Tiv M, Viel JF, Mauny F, et al. Medication adherence in type 2 diabetes: the ENTRED study 2007, a French population-based study. PLoS One. 2012;7(3):e32412.

18. Banerji MA, Dunn JD. Impact of glycemic control on healthcare resource utilization and costs of type 2 diabetes: current and future pharmacologic approaches to improving outcomes. Am Health Drug Benefits. 2013;6(7):382-92.

19. Brod M, Nikolajsen A, Weatherall J, Pfeiffer KM. The economic burden of post-prandial hyperglycemia (PPH) among people with type 1 and type 2 diabetes in three countries. Diabetes Ther. 2016;7(1):75-90.

20. StataCorp. Stata Statistical Software: Release 14. College Station, TX: StataCorp LP; 2015.

21. Kumar M, Gupta S, Liu GG, Stankus AP. Demographics and health outcomes associated with adherence and non-adherence among type 2 diabetics in China. In: ISPOR 6th Asia Pacific conference; PDB31; Beijing, China, 2014.

22. Rubin RR, Peyrot M, Siminerio LM. Health care and patient-reported outcomes: results of the cross-national Diabetes Attitudes, Wishes and Needs (DAWN) study. Diabetes Care. 2006;29(6):1249-55.

23. Sayner R, Carpenter DM, Blalock SJ, et al. Accuracy of patient-reported adherence to glaucoma medications on a visual analog scale compared with electronic monitors. Clin Ther. 2015;37(9):1975-85. 